\title{
Healthcare Seeking Behavior of Mothers or Care Givers for Common Childhood Illness of Under Five Years Children and Associated Factors in Kimbibit District, Ethiopia, 2020
}

\author{
Habtamu Asrat ${ }^{1, ~ *}$, Takele Gezahagn ${ }^{2}$, Zalalem Kaba $^{3}$, Robert Wondimu ${ }^{4}$, Tola Abera ${ }^{5}$ \\ ${ }^{1}$ Kimbibit Woreda Health Office, Sheno, Ethiopia \\ ${ }^{2}$ Department of Public Health, Institute of Health Sciences, Debre Berhan University, Debre Berhan, Ethiopia \\ ${ }^{3}$ East Wollega Zonal Health Office, Nekemte, Ethiopia \\ ${ }^{4}$ Sendafa Beke Town Health Office, Sendafa Beke, Ethiopia \\ ${ }^{5}$ Barak Woreda Health Office, Sendafa Beke, Ethiopia
}

Email address:

habtamuasrat2021@gmail.com (H. Asrat), takele.gez44@gmail.com (T. Gezahagn), kabazalalem@gmail.com (Z. Kaba), robertwondimu@gmail.com (R. Wondimu), tola12abera@gmail.com (T. Abera)

${ }^{*}$ Corresponding author

\section{To cite this article:}

Habtamu Asrat, Takele Gezahagn, Zalalem Kaba, Robert Wondimu, Tola Abera. Healthcare Seeking Behavior of Mothers or Care Givers for Common Childhood Illness of Under Five Years Children and Associated Factors in Kimbibit District, Ethiopia, 2020. Science Journal of Public Health. Vol. 9, No. 4, 2021, pp. 121-134. doi: 10.11648/j.sjph.20210904.12

Received: June 24, 2021; Accepted: July 21, 2021; Published: July 29, 2021

\begin{abstract}
Mothers' healthcare seeking behavior is a mother's response for sign and symptoms of her child illnesses to reduce severity, complication or even death after she recognized child's illness and if she reported visiting any health institutions. Healthcare seeking behavior of mothers or care givers for common childhood illness of under-five children in Kimbibit District, Ethiopia was assessed in this study. A community based cross-sectional study with mixed method approach was employed. Face to face interview for quantitative and focus group discussion for qualitative study were employed. Inductive thematic analysis was employed for qualitative data. For quantitative part, data was checked, cleaned, coded and entered into Epi Data version 3.1 and then, exported to SPSS version 20. Bivariable analysis was done and variables with $\mathrm{p}$-value $<0.25$ on bivariate analysis were entered to multivariable logistic regression model. Significance was checked at $95 \%$ CI with $\mathrm{p}<0.05$. A total of 596 respondents with a response rate of $98.8 \%$ were participated in the study. The overall healthcare seeking behavior of mothers or care givers for common childhood illness was 87.5\% (95\% CI: 84.2\%, 90.6\%). Being urban residents (AOR=2.89; $95 \% \mathrm{CI}=1.83-6.74)$, child's age 12 to 23 months $(\mathrm{AOR}=5.03 ; 95 \% \mathrm{CI}=1.55-9.28)$, mothers who completed primary school (AOR=4.60: 95\% CI; 3.21-6.53), median monthly family income $\geq 1000$ ETB (AOR=4.53; 95\% CI; 3.63-9.26), perceived severity of illness (AOR=2.58; 95\% CI; 0.79-7.33) and distance from health facilities (AOR=6.59; 95\% CI; $2.43-11.85$ ) were the significant predictors of mothers' healthcare seeking behavior for; common childhood illnesses. In this study; it was revealed that healthcare seeking from health facilities was delayed. Place of residence, educational status of mothers or care givers, child's age, average monthly income of family, perceived severity of illness and distance from health facilities were independent predictors of healthcare seeking behaviors.
\end{abstract}

Keywords: Healthcare Seeking Behavior, Common Childhood Illnesses, Kimbibit, Oromia

\section{Introduction}

Mothers' healthcare seeking behavior is defined as mother's response for sign and symptoms of her child illnesses to reduce severity, complication or even death after she recognized child's illness and if she reported visiting any health institutions [1].

Globally, many child deaths are attributed to delays in seeking care, so a timely care seeking practice has a great importance in areas where limited health access. The world health organization estimates that seeking prompt and 
appropriate care by care givers could reduce child death by $20 \%$ [2]. Global evidence indicated that burdens of underfive deaths remains unevenly distributed. About $80 \%$ of the under-five deaths occur in Sub-Saharan Africa (50\%) and Southern Asia (30\%) in 2017. Even though huge disparities in under-five mortality exist across regions and countries, SSA remains the region with the highest under-five mortality rate in the world [3].

Although care seeking interventions have the potential to substantially reduce child mortality in developing countries, large number of children die without ever reaching a health facility and due to delays in seeking care. Inability to recognize potentially life-threatening conditions and pluralistic care-seeking practices were factors of mothers or caregivers to delays in seeking care [4]. Delays in seeking appropriate medical care is one of the major factors contributing to severe disease among children presenting to health facilities with severe cases $[2,5]$.

In Ethiopia, healthcare seeking behavior is poor and only a small proportion of children receive appropriate treatment. Evidence from EDHS showed that only $30 \%$ of under-five children with symptom of ARI, $35 \%$ of with fever and $44 \%$ of with diarrhea were taken health facilities for advice or treatment. This survey also indicated that treatment was sought within the same or next day of onset of illnesses were $3 \%, 8 \%$ and $41 \%$ for ARI, fever and diarrhea, respectively [6]. Some studies also indicated that seeking appropriate and early care for childhood illnesses were low and delayed as well $[1,7,8]$.

Therefore, morbidity and mortality from diseases can be reduced when care is sought early. Ability of mothers or caregivers to recognize and seek appropriate care for these common childhood illnesses is instrumental in reducing child deaths in low-and middle-income countries [4, 9]. Some studies in Ethiopia revealed that maternal education, age of mothers and child, gender, socioeconomic status of the household, perceived severity of illness, number of children under-five years of age in the household, and area of residence were some of the factors related to health care seeking different types of health facilities [7, 10, 11].

Despite some studies in some parts of Ethiopia about mothers or care givers health care seeking behavior for childhood illnesses [1, 4, 8, 9], still there is information gap showing health care seeking behavior for common childhood illnesses including the study setting. Despite the fact that mothers' or care givers' healthcare seeking behavior for childhood illness is essential to reduce underfive morbidity and mortality rate, little is known about factors affecting mothers' or care givers' healthcare seeking behavior on common childhood illnesses in the region and in Kimbibit District particularly. Therefore, the aim of this study is to assess mother's or care givers healthcare seeking behaviors for common childhood illness and associated factors in order to improve child survival in study area.

\section{Methods and Materials}

\subsection{Study Area and Period}

This study was conducted in North Shoa Zone, Kimbibit district, which is one of the districts in Oromia, Ethiopia. It is located about 78 kilo meters (KM) North East of Addis Ababa (the nation capital) and $190 \mathrm{KM}$ far from Fitche town (the capital of North Shoa Zone, Ethiopia). It has latitude and longitude of $9^{\circ} 20^{\prime} \mathrm{N} 39^{\circ} 18^{\prime} \mathrm{E}$ with an elevation of 2918 meters above sea level. Based on the district population projection of $2018 / 2019$, its population estimated to be around 101,950 (females- 51,221) among which 48,457 are reproductive age women (15-49 years). Mothers or caregivers with under five year's age children were estimated to be 16,750. The district contains 29 rural and 2 urban kebeles (smallest administrative unit in Ethiopia). There are 4 governmental health centers, 29 rural and 2 urban health posts, and 4 private clinics in the district [12]. The study was conducted from June 10 to July 12, 2019.

\subsection{Study Design}

A community based cross-sectional study design using mixed methods (quantitative and qualitative approaches) was employed.

\subsection{Populations}

\subsubsection{Source Population}

All mothers or care givers living in Kimbibit district and had under-five children were taken as the source population.

\subsubsection{Study Population}

Mothers or care givers who had at least one under-five child living in selected Kebeles during the study period.

\subsection{Illegibility Criteria}

\subsubsection{Inclusion Criteria}

Mothers or care givers who had at least one under-five child in selected Kebeles during study period.

\subsubsection{Exclusion Criteria}

Mothers or care givers who had been seriously ill during the data collection period.

\subsection{Sample Size Determination and Sampling Technique}

\subsubsection{Sample Size Determination}

a. Quantitative part: The sample size was determined by using single population proportion formula using EpiInfo version 7.2.0.1 Statcalc for sample size calculation. Proportion of healthcare seeking behavior (p) taken from previous study; 58.4\% [9]. Prevalence of healthcare seeking behavior for common childhood illnesses taken from previous different studies and their sample sizes were calculated.

b. Based on the EpiInfo sample size calculations, the larger sample size for both magnitude of healthcare seeking behavior and associated factors was selected. Then, by adding $10 \%$ non-response rate sample size was 603 
(assumptions:-sample calculated for variables that yields large sample, confidence interval at 95\%, design effect 1.5 and non-response rate $10 \%$ were used for this calculation).

c. Qualitative part: A total of six focus group discussions (FGDs); two FGD participants from mothers or care givers and one FGD participants each from community leaders, traditional healers, health extension workers and health care workers were recruited, which were guided by the point of saturation. Purposive sampling method was used to choose a total of 53 FGD participants.

\subsubsection{Sampling Techniques and Procedures}

Multistage sampling technique was used to recruit the respondents. District was classified into two; urban and rural settings. Among twenty-nine rural and two urban Kebeles in the district, eight rural and one urban; a total of nine Kebeles were selected first using lottery method, then a minimum of $50 \%$ of Gots or Ketenas (Got or Ketena is the smallest unit in Kebele Administrative) from the selected Kebeles were selected using simple random sampling method. The sample size was proportionally allocated. One hundred forty nine (149) study subjects were selected from urban while the rest four hundred fifty four (454) were from rural Kebeles. Since cluster sampling technique was used, households were visited to assess the presence of under-five children. Each household was visited until the required sample size was reached. In the cases of more than one index mother of under-five children per household, one mother was selected by using lottery method on the moment [Figure 1].

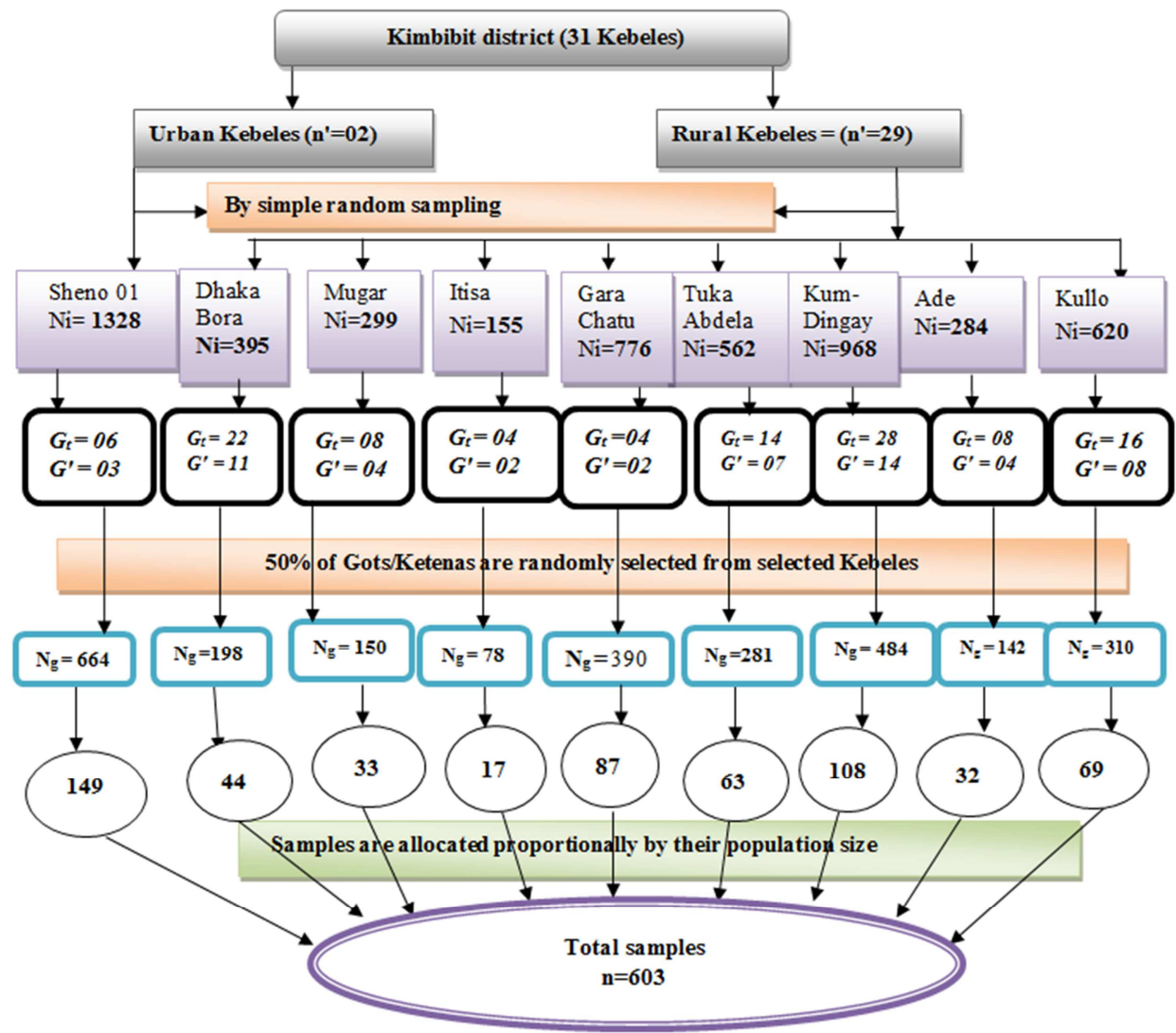

Figure 1. Schematic presentations of household sampling procedures to select sample for the study from Kimbibit district, Ethiopia, June 2019.

Where;

$\mathrm{N}_{\mathrm{i}}=$ Number of mothers or Care givers with under-five children

$\mathrm{N}_{\mathrm{g}}=$ number of mothers or care givers with under-five children in the selected Gots or Ketenas.

$\mathrm{G}_{\mathrm{t}}=$ total number of Gots or Ketenas in the selected Kebeles.

$\mathrm{G}^{\prime}=50 \%$ selected Gots or Ketenas from selected total Gots or Ketenas.

$\mathrm{n}=$ total sample size, $\mathrm{n}^{\prime}=$ Number of kebeles

Qualitative part: FGDs participants includes twenty mothers or care givers with at least one under-five year child, nine each form community leaders and traditional healers, eight Health Extension Workers (HEWs) and seven Health Care Workers (HCWs) trained on Integrated Management of Newborn and Childhood Illnesses (IMNCI) were included. Six FGDs were used from which two FGDs for mothers or care givers; one each FGD from community leaders, traditional healers, health extension workers, and health professionals participants were grouped. A total of 53 participants were selected using purposive sampling for six FGD, each group comprising around 7 to 10 participants. FGDs' participants were recruited one week before the meeting for discussion, through the HEW, and Kebele leader who were informed of the criterion for selection of the FGDs participants. 


\subsection{Variables}

\subsubsection{Dependent Variable}

Healthcare seeking behaviors of mothers or care givers for common childhood illnesses.

\subsubsection{Independent Variables}

a) Socio demographic characteristics of mothers or care givers: age (in years), marital status, education, occupation, family number and income.

b) Demographic characteristics of children: age (in months) and sex of child.

c) Characteristics of illness: severity and symptoms type, sever, mild and moderate.

d) Health service characteristics: availability of health facilities, distance of health facilities and cost of medical care.

\subsection{Operational Definitions}

a) Healthcare seeking behaviour: - is care sought from health institutions; hospitals, health centers, and private clinics for sick child.

b) Appropriate care: Care sought from qualified medical professionals in health facilities and private hospitals or clinics $[8,13]$.

c) Inappropriate care: Other types of care such as purchasing medicines from pharmacy, self-treatment at home (home remedies), visiting pharmacies, Holy water and traditional healers [13].

d) Prompt care: Any type of care that was sought or given within 24 hours from the recognition of the illness [8, 13].

e) Common childhood illnesses: in this study; it includes acute respiratory tract infections, diarrheal diseases and febrile illnesses [14].

f) Acute respiratory tract infection (ARTI): is cough accompanied by short or difficult breathing at any time within the six weeks before the survey for less than two weeks reported by mothers or care givers $[14,15]$.

g) Difficult breathing: is any unusual pattern of breathing (breathing is "fast" or "noisy" or "interrupted") of the sick children described by mothers or caretakers [14].

h) Diarrhea: if the mothers or caretakers described their sick children had loose or watery stools than normal (three or more times) within the six weeks before the survey $[14,15]$.

i) Delay: care that was sought from health facilities after one day (24 hours) [8].

j) Fever: If history of hot body than normal reported by mothers or caretakers for any sick child within the six weeks before the survey [14].

\subsection{Data Processing}

\subsubsection{Data Collection Methods and Tools}

Primary data was collected using structured and pretested questionnaire through face to face interview. The questionnaires contains four sections (socio demographic characteristics, healthcare seeking behaviors, associated factors with healthcare seeking behavior of mothers or care givers of under-five year's age and information about health facility). This questionnaire was taken and modified from different literatures [4, 7-9, 15, 12]. Four diploma Nurses and three BSC Nurses as data collectors, and three health officers as supervisors who are fluent in Afaan Oromo were recruited.

For qualitative: the data collection was employed with FGD exploration through probing question prepared in English version and translated in to Afaan Oromo language. Audio recorder was employed to record FGD interview. Mothers or care givers with at least one under-five year child, community leader, health extension workers selected from each selected Kebeles and health care workers from health centers.

FGDs guide questions including eleven open-ended questions concerning the current childhood health problems, healthcare seeking behavior, and factors affecting healthcare seeking behaviors were used to collect qualitative data. Participants were left to discuss each question actively with as little interference as possible from the principal investigator. The moderator controlled the discussion while assistant wrote the notes and recorded the discussion. The discussions were lasted on average 70 minutes.

\subsubsection{Data Quality Assurance}

For quantitative:-One day training was given for data collectors and supervisors. Pretest was carried out on thirty mothers in Aleltu district before commencing actual data collection. Daily basis discussion with data collectors and supervisors was made so as to check completeness, consistency and quality of data. The completeness of the questionnaires was checked, cleaned, coded and entered into Epi Data version 3.1 prepared templates and then exported to SPSS version 20 for further analysis.

For qualitative: Transcribed, translated and supplemented with field notes. Checked for all the information was properly translated and transcribed, then categorized into themes.

\subsubsection{Data Processing and Analysis}

For quantitative data analysis:- Epi Data template was prepared and the data was checked, cleaned, coded and entered into it, and then exported to (SPSS) version 20 for further analysis. Means, standard deviation and proportions for the different variables was calculated and the data was presented in tables and figures. Bivariable analyses were done to see the association between independent variables and the outcome variable (HCSB). Variables with p-value < 0.25 in bivariable analyses were entered into multivariable analysis model to determine independent predictors of health seeking behavior for common childhood illness according to David W. Hosmer and Stanley Lemeshow recommendation [16]. Then, Odds Ratios (OR) associated with these important factors was explained and reported as a measure of strength, at $95 \% \mathrm{CI}$ and the $\mathrm{p}$-value of $<0.05$ was considered 
statistically significant.

The qualitative data that was obtained from FGD was audio recorded, transcribed, translated and coded. The response was transcribed to Afaan Oromo and translated to English and the main response was categorized into three thematic areas. The main responses from the respondents were reported using narrative and mentioned in direct quotation. Inductive thematic analysis was used to process of analysis and systematically coding based on the request questions. Finally, the narrative qualitative information was organized and integrated according to emerging themes and concepts that was answered the research questions and the results were supplemented with quantitative findings.

\subsection{Ethical Consideration}

Ethical approval was obtained from Ethical Review Committee of Debre Berhan University, College of Health Sciences. A formal letter was written to Kimbibit district health office for permission and support. Official letter was also obtained from district health office and submitted to the selected Kebele administrations. The study participants were informed about the purpose of the study and assure that participation was fully voluntary. Verbal consent was obtained from the participant. Confidentiality and the right of respondents were respected as well as each participant was explained about the purpose of the study. The respondents were assured that information would remain confidential and would be used for the purpose of this study only.

Table 1. Socio demographic characteristics of mothers or caregivers in Kimbibit district, Ethiopia, July, 2019 (n=596).

\begin{tabular}{|c|c|c|}
\hline Variables & Frequency $(\mathbf{N})$ & Percent (\%) \\
\hline \multicolumn{3}{|l|}{ Place of residence } \\
\hline Urban & 147 & 24.7 \\
\hline Rural & 449 & 75.3 \\
\hline \multicolumn{3}{|c|}{ Age of mothers or care givers age (in year) } \\
\hline $18-24$ & 92 & 15.4 \\
\hline $25-34$ & 417 & 70.0 \\
\hline$\geq 35$ & 87 & 4.6 \\
\hline \multicolumn{3}{|l|}{ Marital status } \\
\hline Currently married & 558 & 93.6 \\
\hline Currently not married & 38 & 6.4 \\
\hline \multicolumn{3}{|l|}{ Religion } \\
\hline Orthodox & 532 & 89.3 \\
\hline Muslim & 43 & 7.2 \\
\hline Protestant & 21 & 3.5 \\
\hline \multicolumn{3}{|l|}{ Ethnicity } \\
\hline Oromo & 528 & 88.6 \\
\hline Amhara & 63 & 10.6 \\
\hline Others & 5 & 0.8 \\
\hline \multicolumn{3}{|c|}{ Educational status of mothers or care givers } \\
\hline Illiterate & 257 & 43.1 \\
\hline Primary education & 259 & 43.5 \\
\hline Secondary education and above & 80 & 13.4 \\
\hline \multicolumn{3}{|c|}{ Occupation of mothers or care givers } \\
\hline House wife & 113 & 19.0 \\
\hline Farmer & 415 & 69.6 \\
\hline Others* & 68 & 11.4 \\
\hline \multicolumn{3}{|c|}{ Median monthly income of the family (Ethiopian birr) } \\
\hline$<1000$ & 330 & 55.4 \\
\hline$>=1000$ & 266 & 44.6 \\
\hline \multicolumn{3}{|l|}{ Family size } \\
\hline$<5$ & 433 & 72.7 \\
\hline $5-7$ & 114 & 19.1 \\
\hline$\geq 8$ & 49 & 8.2 \\
\hline \multicolumn{3}{|l|}{ Number of under five children } \\
\hline 1 & 486 & 81.5 \\
\hline$\geq 2$ & 110 & 18.5 \\
\hline \multicolumn{3}{|c|}{ Relationship of mother or care giver with child } \\
\hline Mother & 585 & 98.2 \\
\hline Others $^{\wedge}$ & 11 & 1.8 \\
\hline
\end{tabular}

*Others include merchant, daily worker, government employee and private employee; ^ other includes care giver and grandmother. 


\section{Result}

\subsection{Socio Demographic Characteristics}

A total of 596 mothers or caregivers (98.8\% response rate) were participated in the study. The median age of mothers or care givers interviewed was $28(\mathrm{SD} \pm 12.8)$ years. Majority of them $449(75.3 \%)$ were from rural residents. Majority them were Orthodox in religion $(532,89.3 \%)$ and from Oromo ethnic group $(528,88.6 \%)$. About $486(81.5 \%)$ mothers or care givers had one under-five children in their house. With regard to the relationship of respondents with child, 585 $(98.2 \%)$ were mothers [Table 1$]$.

For qualitative method:-a total of fifty-three discussants were participated in six FGDs; each consisting 7 to 10 discussants. Participants were predominantly females, aged between 21 and 56 years. Majority of FGD participants had no formal education. Findings of the FGDs was categorized under three thematic areas:- common childhood illnesses in area, healthcare seeking behaviors and associated factors for healthcare seeking behaviors and triangulated with the results of quantitative method.

\subsection{Child's Demographic Characteristic}

Out of the total, $296(49.7 \%), 239$ (40.1\%), and $61(10.2 \%)$ children were in the age group of 24 to 59,12 to 23 , and $<11$ months respectively. More than half, 332 (55.7\%) of the children were males and 264 (44.3\%) were females.

\subsection{Common Childhood Illnesses}

Concerning symptom of illness experienced by the children in the last six weeks preceding the survey, 424 (71.1\%) of the children experienced any symptoms of illness. Of this, one hundred fifty six $(36.9 \%)$ were perceived as severe symptoms by mothers or caregivers whereas 189 $(44.7 \%)$ and $79(18.4 \%)$ were perceived as moderate and mild respectively. Regarding particular symptoms of illness experienced by the children, $223(52.6 \%)$ experienced fever, $151(35.6 \%)$ cough with difficulty of breathing (suggestive symptom of ARI), and 50 (11.8\%) diarrhea [Table 2].

Table 2. Child health-related information in Kimbibit district, Ethiopia, July 2019 (n=596).

\begin{tabular}{|c|c|c|}
\hline Variables & Frequency (N) & Percent (\%) \\
\hline \multicolumn{3}{|c|}{ Any symptoms experienced by children in the last six weeks $(n=594)$} \\
\hline Yes & 424 & 71.1 \\
\hline No & 172 & 28.9 \\
\hline \multicolumn{3}{|c|}{ Kinds of symptoms experienced by the children in the last six weeks $(n=424)$} \\
\hline \multicolumn{3}{|c|}{ Cough with difficulty of breathing } \\
\hline Yes & 151 & 35.6 \\
\hline No & 273 & 64.4 \\
\hline Yes & 223 & 52.6 \\
\hline No & 201 & 43.4 \\
\hline \multicolumn{3}{|l|}{ Diarrhea } \\
\hline Yes & 50 & 11.8 \\
\hline No & 374 & 88.2 \\
\hline \multicolumn{3}{|c|}{ Perception of mothers or caregivers about severity of illness } \\
\hline Severe & 156 & 36.9 \\
\hline Moderate & 189 & 44.7 \\
\hline \multicolumn{3}{|c|}{ How do mothers or care givers identify the severity of illness on their child? } \\
\hline By combined symptoms of the disease & 308 & 72.6 \\
\hline By child's refusal to eat & 55 & 13.0 \\
\hline The illness continue for long time & 33 & 7.8 \\
\hline Others* & 28 & 6.6 \\
\hline
\end{tabular}

*Other includes: grand parents and relatives.

\subsection{The Qualitative Finding of the Study Supported the Above Findings}

The major childhood illnesses among under-five children identified by FGD participants were "Michii sombaa, Gaara kaasaa, Bu'aa, Huuba qonqoo, Gubaa qaama and Qufaa." illnesses mentioned by their local names. FGD number 1, 2 and 3 (mothers or care givers, community leaders).

Participants made several distinctions in these child illnesses based on local perceptions of illness. The most common distinction was between signs and symptoms that were frequently recognized in the communities described by FGD participants.
Gaara kaasaa: This type of diarrhea was believed that it caused due to unsafe food, poor personal hygiene, contaminated water, and eating uncooked food. This type of illness was characterized by persistent loss of stool, lethargy and loss of weight.

Bu'aa: A type of diarrhea believed that to happen when child falls down. This condition was characterized by grunting, persisted cry, difficulty of opening eye lid, vomiting and lethargy.

Michii sombaa: The term 'Michii sombaa' was used to denote pneumonia. A symptom of illness was characterized by cough, high fever, unable to suck breast and gasping. 
Huuba qonqoo: The term was used to represent tonsillitis in children. A symptom of illness was characterized by swollen tonsils, sore throats, fever, difficulty of swallowing and unable to feed.

Gubaa qaama: The term was used to denote fever. This condition was characterized by high body temperature unable to eat, weakness and sleeplessness.

Qufaa: the term 'Qufa' was used to indicate common cold/flu. Symptoms of this illness commonly characterized by sneezing, cough, headache, fever, loss of appetite and sore throat. FGD number 1, 2, and 3 (mothers or care givers, community leaders).

\subsection{Healthcare Seeking Behavior for Common Childhood Illnesses}

In this study, the overall healthcare seeking behavior of mothers or care givers was $87.5 \%$ (95\% CI: $84.2 \%, 90.6 \%)$. Out of 424 mothers or care givers with children who had got illness preceding the survey, $371(87.5 \%)$ reported their preferred sources of healthcare for childhood illnesses was health facilities whereas $51(12.0 \%)$ were preferred other sources and $2(0.5 \%)$ mothers or care givers did nothing for their children. Among 371 mothers or care givers, 219 $(59.0 \%)$ of decision made by both mothers and fathers for medical care [Table 3].

Table 3. Mothers or caregivers healthcare seeking behavior for common childhood illnesses in Kimbibit district, Ethiopia, July 2019 (n=596).

\begin{tabular}{|c|c|c|}
\hline Variables & Frequency $(\mathbf{N})$ & Percent (\%) \\
\hline \multicolumn{3}{|l|}{ From where care sought for the sick children $(n=424) ?$} \\
\hline From government health facilities & 260 & 61.3 \\
\hline From private health facilities & 111 & 26.2 \\
\hline From traditional healers & 20 & 4.7 \\
\hline Self-treatment at home & 11 & 2.6 \\
\hline Treatment with drugs bought from pharmacies or drug sellers & 9 & 2.1 \\
\hline Treat with Holy Water & 11 & 2.6 \\
\hline \multicolumn{3}{|l|}{ Who decided to take the child for medical care/treatment? $(n=371)$} \\
\hline Child's mother or care giver & 107 & 28.8 \\
\hline Child's father & 33 & 8.9 \\
\hline Both mother and father & 219 & 59.0 \\
\hline Others & 12 & 3.3 \\
\hline \multicolumn{3}{|c|}{ Main reasons of mothers or care givers for not seeking medical care $(n=424)$} \\
\hline Thought it would get better by itself & 185 & 43.6 \\
\hline Lack of immediate care or long waiting time & 26 & 6.1 \\
\hline Previous bad experience with medical care & 15 & 3.5 \\
\hline Thought sickness is incurable by modern medicine & 41 & 9.7 \\
\hline Others** & 6 & 1.4 \\
\hline \multicolumn{3}{|l|}{ Mothers seeking to traditional healers $(n=594)$} \\
\hline Yes & 193 & 32.4 \\
\hline No & 403 & 67.6 \\
\hline \multicolumn{3}{|l|}{ Main reasons for seeking traditional healers or medicine $(n=193)$} \\
\hline Don't get cure from medical care & 21 & 10.9 \\
\hline They do not charge too much & 77 & 39.9 \\
\hline There is no long waiting time & 54 & 28.0 \\
\hline Treatment is effective & 18 & 9.3 \\
\hline Others $* * *$ & 23 & 11.9 \\
\hline
\end{tabular}

**other includes no treatment for the sickness and shortage of money; ***other:-maintain confidentiality, recommended by family member and maintain privacy.

\subsection{These Findings Were Supported Findings Obtained from $F G D$}

Participants of FGD indicated that "Diarrhea and cough are the most serious; common childhood health problems in the area. Sometimes, tonsillitis is observed on children aged two to three years frequently in our community." FGD number (\#) 1, 2 (Mothers or care givers).

Similarly, a trained and experienced health officer with IMNCI and working in health center pointed out that "Diarrhea and cough with difficulty of breathing are the most common causes of morbidity whereas acute febrile illness is the following cause of morbidity among under-five children.
"FGD\#6 (HCWs).

Among 424 children who had been ill in the last six weeks before the survey, any care was sought for 422 (99.5\%) children from elsewhere whereas $2(0.5 \%)$ of ill children didn't get any help. Health facilities (both government and private health facilities), were the most common sources, 371 $(87.5 \%)$ where care was sought for the sick children. Moreover, mothers or care givers sought traditional healer for $20(4.7 \%)$ children, treated with Holy Water 11 (2.6\%), made self-treatment at home $11(2.6 \%)$, and treatment with drugs bought from pharmacies or drug sellers 9 (2.1\%) for their sick children (Table 4). Results were triangulated with FGD findings:

FGD participants said that if the child experienced diarrhea 
they took their children to traditional healer first than health care facilities for different reasons as the following quotes shows:

"When my child gets diarrhea, first, I suspect that it might be 'bu'a'. So I take her to a traditional healer locally called 'Ogeetti or Wogesha' on the next day. But if diarrhea is not due to bu'a and illness become severe, then I take her to the health center."FGD\#1 (Mothers or care givers).

One FGD participants responded that "I try to treat him at home for diarrhea, however if the child's condition is not get better and illness persists, then I take him to health facility." She also explained that "Usually children more than two years old when playing outside may fall down. In this case, diarrhea caused due to fall down of children locally known as 'bu'a' does not need modern medicine rather traditional healer 'Ogeetti or Wogesha' is better option in our village."FGD\#2 (Mothers or care givers).

From FGD participants, a 26 years old mother said that "My child had cough for a week. I told my mother-in-law that my child had cough and she advised me not go health institution anywhere because this illness does not need medical care. First we took him to holy water locally called 'Tsebal'. But he did not show any improvement for three days rather illness became severe and persisted; then we came back and took him to health center after three days. They gave medicine for seven days. He had recovered after a week."FGD\#2 (Mothers or care givers).

This survey also identified the magnitude of healthcare seeking behavior for common childhood illnesses. Of the total children presented with particular symptoms of illnesses, more medical care was sought when children presented with diarrhea $45(90 \%)$ followed by fever $196(87.9 \%)$ and ARI $130(86.1 \%)$.

As reported by the respondents, the main reasons for visiting health facilities includes; child's condition worsened $263(70.9 \%)$, in order not the child's condition worsened 94 (25.3\%), other peoples' advise $13(3.5 \%)$ and due to others reason $1(0.3 \%)$.

Among 424 mother or care givers, 219 (59.0\%) reported that both mothers and husbands made decision for seeking medical care, while 107 (28.8\%) of mothers made decision by their own when their child got illness [Table 3].

These Findings Were Triangulated with the Findings from FGD as Follows:

A 32 years old mother explained that "My child had high fever locally known as 'guba cima' and refused breast feeding. He was crying as unusual and restless. I realized that my child had got sick. I told my husband we must not wait more time; his illness became worsening. Then we decided to take him to private clinic immediately. We arrived after an hour at clinic. A nurse measured his temperature and told us his temperature was high. He gave him medicines; he became well after a day, "FGD\#1 (mothers or care givers).

Regarding the time of care seeking, among 371 mothers who sought care from health facilities, only 117 (31.5\%) mothers or care givers were sought care from health facilities on the same day of recognition of illnesses, whereas 254
$(68.5 \%)$ of mothers or care givers were sought care from health facilities after one day of recognition of the illnesses. This showed that nearly three-fourth of healthcare seeking was delayed.

These Findings Triangulated by FGD Response as Follow:

One of the traditional healer from FGD participants explained that "I was worked as 'Ogeetti or Wogesha' for more than 20 years in this area. As my experience, most mothers are more experienced to recognize any symptom of illness when their children had got illness. But majority of them whose children become sick take their children to traditional healer or other health institutions too late," FGD\#4 (Traditional healers).

Four hundred twenty four mothers or caregivers who did not seek any care from health facility are asked for reasons. Perception that illness would get better by itself 185 (43.6\%) and cost of medical care $100(23.6 \%)$ were the main reasons given for failure to seek care from health facilities by the mothers or care givers. The remaining $51(12.0 \%)$ was due to transportation difficulties, thought sickness is incurable by modern medicine $41(9.7 \%)$, don't get immediate care or waiting time $26(6.1 \%)$, Previous bad experience with medical care 15 (3.5\%), and other 6 (1.4\%) (Table 3).

These Quantitative Finding Were Supported by Qualitative Responses as Follow:

A 56 years old man from community leaders said that "Most mothers wait, they think that child's condition will get better by itself and certain mothers may not have money in pocket for treatment." He also stated that "In our kebele it is difficult to take children to health facilities early after onset of illness; because we do not have access to road for transportation as other kebeles,"FGD\#3 (Community leaders).

Among 596 mothers or care givers interviewed, 193 (45.5\%) mothers were seeking traditional healers for their sick child and their main reasons for seeking traditional healers, $77(39.9 \%)$ they believed that they do not charge too much whereas $54(28.0 \%)$ believed that there is no long waiting time [Table 3].

\subsection{Factors Associated with Mothers' or Care Givers' Healthcare Seeking Behavior for Common Childhood Illnesses}

In bivariable logistic regression, it was indicated that place of residence $(\mathrm{COR}=3.15 ; 95 \% \mathrm{CI}: 2.02,4.93)$, sex of child $(\mathrm{COR}=2.21 ; 95 \% \mathrm{CI}: 1.58,3.10)$, age of mothers or care givers $(\mathrm{COR}=2.14 ; 95 \% \mathrm{CI}: 1.34,3.42)$, age of child $(\mathrm{COR}=5.66$; 95\% CI: 3.22, 9.93), family size $(\mathrm{COR}=3.60$; $95 \%$ CI: $1.1 .96,6.63)$, educational status of mothers or care givers with primary education $(\mathrm{COR}=3.18 ; 95 \% \mathrm{CI}: 2.20$, 4.60); secondary education $(\mathrm{COR}=4.54 ; 95 \% \mathrm{CI}: 2.40$, 8.60); and diploma and above $(\mathrm{COR}=5.89$; 95\% CI: 1.27 , $7.42)$ average family monthly income $(\mathrm{COR}=4.38 ; 95 \% \mathrm{CI}$ : $3.02,6.34)$, perceived severity of the illness; severe $(\mathrm{COR}=3.60 ; 95 \% \mathrm{CI}: 1.63,7.93)$ and moderate $(\mathrm{COR}=2.28$; 95\% CI: $1.14,4.54)$, distance from health facility; walking time less than 30 minutes $(\mathrm{COR}=5.39 ; 95 \% \mathrm{CI}: 3.53,8.22)$ and walking time 30 to 60 minutes $(\mathrm{COR}=3.56 ; 95 \% \mathrm{CI}$ : 
$2.32,5.48)$ were significantly associated with healthcare seeking behaviors [Table 4].

Table 4. Associated factors of health care seeking behavior for common childhood illnesses in Kimbibit district, Ethiopia, July 2019 (n=596).

\begin{tabular}{|c|c|c|c|c|}
\hline \multirow{2}{*}{ Variables } & \multicolumn{4}{|c|}{ Healthcare seeking behavior } \\
\hline & Yes, $(\%)$ & No, $(\%)$ & COR $(95 \% \mathrm{CI})$ & P-value \\
\hline \multicolumn{5}{|l|}{ Place of residence } \\
\hline Urban & $118(19.8)$ & $29(4.9)$ & $3.15(2.02,4.93)^{* *}$ & $<0.001$ \\
\hline Rural & $253(42.4)$ & $196(32.9)$ & 1 & \\
\hline \multicolumn{5}{|l|}{ Sex of child } \\
\hline Male & $234(39.3)$ & $98(16.4)$ & $2.21(1.58,3.10)^{* *}$ & $<0.001$ \\
\hline Female & $137(23.0)$ & $127(21.3)$ & 1 & \\
\hline \multicolumn{5}{|c|}{ Age of mothers or care givers (in year) } \\
\hline $18-24$ & $51(8.6)$ & $41(6.9)$ & $1.33(0.74,2.40)$ & 0.338 \\
\hline 25-34 & $278(46.6)$ & $139(23.3)$ & $2.14(1.34,3.42)^{*}$ & 0.001 \\
\hline$\geq 35$ & $42(7.0)$ & $45(7.6)$ & 1 & \\
\hline \multicolumn{5}{|c|}{ Age of child (in months) } \\
\hline$\leq 11$ & $24(4.0)$ & $37(6.2)$ & $0.76(0.38,1.51)$ & 0.431 \\
\hline $12-23$ & $198(33.2)$ & $41(6.9)$ & $5.67(3.22,9.93)^{* *}$ & $<0.001$ \\
\hline $24-35$ & $88(14.8)$ & $68(11.4)$ & $1.52(0.87,2.63)$ & 0.139 \\
\hline $36-47$ & $26(4.4)$ & $38(6.4)$ & $0.80(0.41,1.57)$ & 0.519 \\
\hline$\geq 48$ & $35(5.9)$ & $41(6.8)$ & 1 & \\
\hline \multicolumn{5}{|l|}{ Family size } \\
\hline$<5$ & $301(50.5)$ & $132(22.4)$ & $3.60(1.96,6.63)^{* *}$ & $<0.001$ \\
\hline $5-7$ & $51(8.6)$ & $63(10.6)$ & $1.28(0.65,2.53)$ & 0.481 \\
\hline$\geq 8$ & $19(3.2)$ & $30(5.0)$ & 1 & \\
\hline \multicolumn{5}{|c|}{ Number of children less than five years in family } \\
\hline 1 & $336(56.4)$ & $150(25.2)$ & $5.04(1.53,16.62)^{*}$ & 0.008 \\
\hline 2 & $31(5.2)$ & $66(11.1)$ & $1.06(0.30,3.70)$ & 0.931 \\
\hline$\geq 3$ & $4(0.7)$ & $9(1.5)$ & 1 & \\
\hline \multicolumn{5}{|c|}{ Educational status of mothers or care givers } \\
\hline Illiterate & $118(19.8)$ & $139(23.3)$ & 1 & \\
\hline Primary education & $189(31.7)$ & $70(11.7)$ & $3.18(2.20,4.60)^{* *}$ & $<0.001$ \\
\hline Secondary education & $54(9.10)$ & $14(2.3)$ & $4.54(2.40,8.59)^{* *}$ & $<0.001$ \\
\hline Diploma and above & $10(1.7)$ & $2(0.40)$ & $5.89(1.27,7.42)^{*}$ & 0.024 \\
\hline \multicolumn{5}{|c|}{ Average monthly income of family in Ethiopian Birr } \\
\hline$<1000$ & $158(26.5)$ & $172(28.9)$ & 1 & \\
\hline$\geq 1000$ & $213(35.7)$ & $53(8.9)$ & $4.38(3.02,6.34)^{* *}$ & $<0.001$ \\
\hline \multicolumn{5}{|l|}{ Perception of severity } \\
\hline Sever & $144(34.0)$ & $12(2.8)$ & $3.60(1.63,7.93)^{*}$ & 0.001 \\
\hline Moderate & $167(39.5)$ & $22(5.2)$ & $2.28(1.14,4.54)^{*}$ & 0.019 \\
\hline Mild & $60(14.2)$ & $18(4.3)$ & 1 & \\
\hline \multicolumn{5}{|c|}{ Distance from health facility/estimated walking time to reach nearest health facility } \\
\hline$<30$ minutes & $173(29.0)$ & $50(8.4)$ & $5.39(3.53,8.22)^{* *}$ & $<0.001$ \\
\hline 30-60 minutes & $119(20.0)$ & $52(8.7)$ & $3.56(2.32,5.48)^{* *}$ & $<0.001$ \\
\hline$>60$ minutes & $79(13.3)$ & $123(20.6)$ & 1 & \\
\hline
\end{tabular}

*Indicates statistically significant at $\mathrm{p}<0.05$ while $* *$ indicates statistically significant association at $\mathrm{p}<0.001$.

In multivariate logistic regression; place of residence, age of child, educational status of mothers or care givers, average family monthly income, perception of severity and distance from health facilities were significantly associated with healthcare seeking behavior. It indicated that urban resident mothers or care givers were nearly three times more likely to seek healthcare than rural resident mothers $(\mathrm{AOR}=2.89 ; 95 \%$ CI: $1.83,6.74)$. Mothers or care givers who had children 12 to 23 months of age were about five times more likely to seek medical care than those having children greater than or equal to 48 months old ( $\mathrm{AOR}=5.03 ; 95 \%$ CI: $1.55,9.28$ ). Mothers who had completed primary education were nearly five times more likely to seek healthcare than illiterate mothers (AOR=4.60; 95\% CI: 3.21, 6.53) [Table 5].

These Findings Were Supported by Findings from FGD Quotation Shows:

A 6 years experienced BSc nurse in IMNCI said that
"Usually mothers from rural areas may not go anywhere till morning if their children get sick during night. Because they far away from health facilities. Even they do not get transportation facilities whenever they want. He also added that "If they have money in pocket they will not go to health center after a day. Such children usually come to our health center with severe cases or complications," FGD\#6 (HCWs).

Mothers or care givers from households with median family monthly income above or equal to median income of 1000 Ethiopian birr had 4.53 times more likely to seek medical care for their ill children than those who earn below median income (AOR=4.53; 95\% CI: 3.63, 9.26). Mothers or care givers who perceived their child's illnesses was sever around three times more likely to seek health care compared to illness was mild (AOR=2.58; 95\% CI: 0.79, 7.33). Mothers or care givers who were with in short distance from the nearest health facilities (less than 30 minutes on walking 
to arrive health facilities) had nearly seven times more likely to seek medical care than those have time of walking more than 60 minutes $(\mathrm{AOR}=6.59 ; 95 \% \mathrm{CI}: 2.43,11.85)$ [Table 5].

This Finding Was Supported by Findings from FGD as Following Quotation Shows:

During FGD one of the participants said that "Most mothers living far away from health facilities walk a long distance. Walking is the only option to go there and if mothers think of the distance they have to travel, they wait more than a day," FGD\#3 (Community leaders).

A health extension worker from FGD participants explained that "Mothers do not want to health center early when their children had got illness because of the distance from health facilities. In our case, the nearest health center takes more than an hour walking from our kebele," FGD\#5 (HEWs).

Table 5. Predictors of healthcare seeking behavior for common childhood illnesses in multivariable regression analysis Kimbibit district, Ethiopia, July 2019 $(n=596)$.

\begin{tabular}{|c|c|c|c|}
\hline \multirow{2}{*}{ Variables } & \multicolumn{2}{|c|}{ Healthcare seeking behavior } & \multirow{2}{*}{$\operatorname{AOR}(95 \%$ CI) } \\
\hline & Yes, N (\%) & No, N (\%) & \\
\hline \multicolumn{4}{|l|}{ Place of residence } \\
\hline Urban & $118(19.8)$ & $29(4.9)$ & $2.89(1.83,6.74)^{* *}$ \\
\hline Rural & $253(42.4)$ & $196(32.9)$ & 1 \\
\hline \multicolumn{4}{|l|}{ Sex of child } \\
\hline Male & $234(39.3)$ & $98(16.4)$ & $2.01(0.92,4.37)$ \\
\hline Female & $137(23.0)$ & $127(21.3)$ & 1 \\
\hline \multicolumn{4}{|c|}{ Age of mothers or care givers (in year) } \\
\hline $18-24$ & $51(8.6)$ & $41(6.9)$ & $3.87(0.81,8.45)$ \\
\hline $25-34$ & $278(46.6)$ & $139(23.3)$ & $1.99(0.85,4.67)$ \\
\hline$\geq 35$ & $42(7.0)$ & $45(7.6)$ & 1 \\
\hline \multicolumn{4}{|c|}{ Age of child (in months) } \\
\hline$\leq 11$ & $24(4.0)$ & $37(6.2)$ & $0.75(0.18,3.16)$ \\
\hline $12-23$ & $198(33.2)$ & $41(6.9)$ & $5.03(1.55,9.28)^{* *}$ \\
\hline $24-35$ & $88(14.8)$ & $68(11.4)$ & $2.55(0.82,7.89)$ \\
\hline $36-47$ & $26(4.4)$ & $38(6.4)$ & $1.06(0.23,4.76)$ \\
\hline$\geq 48$ & $35(5.9)$ & $41(6.8)$ & 1 \\
\hline \multicolumn{4}{|c|}{ Number of family members } \\
\hline$<5$ & $301(50.5)$ & $132(22.4)$ & $1.43(0.37,5.54)$ \\
\hline $5-7$ & $51(8.6)$ & $63(10.6)$ & $0.78(0.21,2.88)$ \\
\hline$\geq 8$ & $19(3.2)$ & $30(5.0)$ & 1 \\
\hline \multicolumn{4}{|c|}{ Number of children less than five years in family } \\
\hline 1 & $336(56.4)$ & $150(25.2)$ & $5.13(0.31,8.17)$ \\
\hline 2 & $31(5.2)$ & $66(11.1)$ & $1.74(0.20,4.87)$ \\
\hline$\geq 3$ & $4(0.7)$ & $9(1.5)$ & 1 \\
\hline \multicolumn{4}{|c|}{ Educational status of mothers or care givers } \\
\hline Illiterate & $118(19.8)$ & $139(23.3)$ & 1 \\
\hline Primary education & $189(31.7)$ & $70(11.7)$ & $4.60(1.21,6.53)^{* *}$ \\
\hline Secondary education & $54(9.10)$ & $14(2.3)$ & $2.72(0.92,5.35)$ \\
\hline Diploma and above & $10(1.7)$ & $2(0.40)$ & $3.92(0.07,9.53)$ \\
\hline \multicolumn{4}{|c|}{ Average monthly income of family } \\
\hline$<1000$ & $158(26.5)$ & $172(28.9)$ & 1 \\
\hline$\geq 1000$ & $213(35.7)$ & $53(8.9)$ & $4.53(1.63,9.26)^{* *}$ \\
\hline \multicolumn{4}{|l|}{ Perception of severity } \\
\hline Sever & $144(34.0)$ & $12(2.8)$ & $2.58(1.79,7.33)^{* *}$ \\
\hline Moderate & $167(39.5)$ & $22(5.2)$ & $1.10(0.42,2.89)$ \\
\hline Mild & $60(14.2)$ & $18(4.3)$ & 1 \\
\hline \multicolumn{4}{|c|}{ Distance from health facility or estimated walking time to reach nearest health facility } \\
\hline$<30$ minutes & $173(29.0)$ & $50(8.4)$ & $6.59(2.43,11.85)^{* *}$ \\
\hline 30-60 minutes & $119(20.0)$ & $52(8.7)$ & $3.04(1.26,7.32)$ \\
\hline$>60$ minutes & $79(13.3)$ & $123(20.6)$ & 1 \\
\hline
\end{tabular}

$* *$ Shows statistically significant association at $\mathrm{p}<0.05$ on multivariable analysis.

\section{Discussion}

This study aimed to assess healthcare seeking behavior of mothers or care givers for common childhood illness of under-five year's children and associated factors in Kimbibit district, Ethiopia. This study revealed the overall healthcare seeking behavior was $87.5 \%$ (95\% CI: $84.2 \%, 90.6 \%)$. It is similar with finding of a study conducted in Derra district, Ethiopia which was $87 \%$ [1]. In contrast, it is higher than finding of a study done in Bure and Jeldu district, Ethiopia [8]. However, it is slight lower than finding of a study conducted in Bengal, Urban Slum of Dhaka city 91\% [17]. These differences might be due to differences in sociodemographic characteristics, and study period. This study also found that mothers or care givers healthcare seeking practices for childhood illnesses were influenced by place of residence, age of child, educational status of the mother or care givers, average family monthly income, perceived 
severity of illness and distance from health facilities.

This study found that the preference of healthcare from health facilities and the actual healthcare seeking practices reported by mothers or care givers was similar for common childhood illnesses. According to this study, healthcare was sought from health facilities for $87.5 \%$ when their child got illness which slightly lower than a study conducted in Urban Slum of Dhaka City, which is (91\%) [17]. Nevertheless, this finding is higher compared with studies conducted in different parts of Ethiopia [8, 9, 15, 18]. These differences might be due to access of information, educational level, study settings and period.

In this study, any care was sought for about $99.5 \%$ for children who had been ill in the last six weeks before the survey and $53(12.00 \%)$ of the mothers or care givers sought care from other sources other than health facilities. It is slightly consistent with a study done in Dengila town, NorthWest Ethiopia in which care $13.5 \%$ mothers care givers were sought from different sources other than health facilities [4]. But, lower than studies conducted in different areas of Ethiopia [10, 7, 8, 19].

Healthcare seeking behavior of the mothers or caregivers was related to particular symptoms of illness and their perceived severity of illness. This finding indicated that mothers or care givers sought care from health facilities for $90 \%, 87.9 \%$ and $86.1 \%$ diarrhea, fever and suggestive symptoms of ARI respectively. It is higher than study done in Jeldu district, Ethiopia in which $81.1 \%, 79 \%$ and $77.6 \%$ with diarrhea, fever and ARI respectively were taken health facilities [8]. But, slight differences with the study done in rural Tanzania [20]. This slight difference might be attributable to perceived severity attached to the illnesses, low traditional practice, access information and study period.

It was reported in this study, despite the frequent sought of healthcare from health facilities $(87.5 \%)$ for common childhood illnesses, there were delaying seeking healthcare from health facility for children presented with symptoms of ARI, fever and diarrhea. For instance, only $31.5 \%$ of the mothers or care givers sought healthcare from health facilities for sick children within 24 hours after recognition of the illnesses and of the total who sought care from health facilities, $70.9 \%$ were initiated when child's symptoms of illness was worsened. It is almost similar with finding of a study done in Yemen (30.19\%) [21]. A study conducted in different settings in Ethiopia also reported that seeking prompt and appropriate healthcare for these illnesses was delayed $[10,7,8]$. The possible reasons of delayed healthcare seeking might be due to thought it would get better by itself, cost of medical care, transportation difficulties, thought sickness is incurable by modern medicine, don't get immediate care or wait several times and previous bad experience with medical care.

It was revealed by this study, the perceptions of illnesses thought it would get better by itself $(43.6 \%)$ and costs of medical care $(23.6 \%)$ were the main reasons for not seeking care from health facility. This study slightly consistent with a study done in Addis Ababa and Yemen [22, 21]. In contrary, it was lower than study conducted in Aneded district, Ensaro district, Bure district and Shire town [10, 7 , 18, 23].

Regarding traditional healers, (32.4\%) mothers or care givers sorting traditional healers when their child got illness. The main reasons were due to they do not charge too much $(39.9 \%)$, there is no long waiting time $(28.0 \%)$ and the treatment is effective $(9.3 \%)$. This result was consistent with study done in Ensaro district, Amhara region [7].

The finding from the multivariable analysis showed that residence of mothers or care givers $(\mathrm{AOR}=2.89 ; 95 \% \mathrm{CI}$ : $1.83,6.74$ ) was associated with healthcare seeking behavior in which mothers or care givers who live in urban were nearly three times more likely seek healthcare than rural mothers. This finding is consistent with a study done in Ensaro district $(\mathrm{AOR}=6.75,95 \% \mathrm{CI} ; 2.97,15.33)$ and North Shoa, Derra district $(\mathrm{AOR}=5.58,95 \% \mathrm{CI}: 2.05,15.2)$ in which mothers or care givers living in urban areas sought more healthcare than mothers living in rural areas $[1,7]$. This might be due to the accessibility of healthcare facilities and information about the importance of seeking healthcare for urban dwellers.

Mothers or care givers who had children aged 12 to 23 months were five times more likely to seek healthcare compared to those who had children older age $(\mathrm{AOR}=5.03$, 95\% CI: 1.55, 9.28). A similar study done in Aneded district and Dendi district showed that mothers or care givers who had children less than two years $(<2$ yrs) were more likely to seek healthcare compared to those with older children [10, 11]. This might be due to mothers understanding that children illnesses were severe in younger compared to older children.

In this study, educational status of mothers found to be another associated factor for healthcare seeking behaviors of mothers or care givers. Healthcare seeking behavior is significantly higher among mothers or care givers with primary level of education $(\mathrm{AOR}=4.60,95 \% \mathrm{CI} ; 3.21$, $6.53)$ compared to those who were illiterate. This finding could also be supported by a similar study conducted in Dengila Zuria Woreda, North West Ethiopia [24]. A similar study from Yemen also revealed that mothers sought medical care significantly more when they had a higher level of school education $(\mathrm{POR}=5.85,95 \% \mathrm{CI}: 2.34$, 14.61) [21].

Households with median monthly income greater or equal to 1000 birr ( $\geq 1000 \mathrm{ETB}$ ) were nearly five times more likely to seek healthcare as compared to their counterpart. The previous study conducted in different parts of Ethiopia revealed that households with higher monthly income were more likely to seek healthcare for their children than those had lower income $[9,22,25]$. Similarly, a study done in Bangladesh indicated that a wealth status of mother was significant determining factor for healthcare seeking behaviors [26]. The possible justification could be better income and awareness about appropriate care is enabling factor for healthcare seeking behavior. 
In this finding, mothers or care givers perceived illness ( $\mathrm{AOR}=2.58,95 \% \mathrm{CI} ; 0.79,7.33$ ) severe was more than two and half times more likely to seek healthcare than mothers who perceive the illness was mild and a similar study conducted in Jeldu district, Oromia region and Dengila town, Amhara region, Ethiopia, mothers perceived their child's illness severe was sought care $3.20(\mathrm{AOR}=3.20,95 \% \mathrm{CI}$ : $1.96,5.22)$ and $5.2(\mathrm{AOR}=5.2,95 \% \mathrm{CI}: 1.2,22.6)$ times more than mild's one respectively $[4,8]$. Similarly a systematic review done in developing countries and study carried out in Yemen showed that mothers more likely to seek medical care when disease conditions were sever [22, 27]. This difference might be due to mothers' fear towards severity of illness and its complication.

Moreover, availability of health facilities within 30 minutes walking distance to the nearest health facility was another predictor for healthcare seeking behavior. This result pointed out that households within 30 minutes walking distance from the nearest health facility sought healthcare seven times more likely to seek care than those living above 60 minutes walking distance (AOR=6.59, 95\% CI: 2.43 , 11.85). Some studies done in parts of Ethiopia showed that households who were lived near a health facility were more likely to visit the health facility at the time of illness than those who lived far [7, 9, 22]. Another study done in Rural Tanzania and Kenya also indicated that participants who were located near to a health facility were more likely to visit the health facility at the time of illness than those who lived far [21, 28]. Similarly, a study conducted in Chitwan district, Nepal; mothers' who were residing less an hour walking distance from health facility were more likely to seek formal healthcare than those who resided more than half an hour distance from the nearest health facility [29]. The possible reasons might be accessibility and physical proximity of health facility are enabling factors to develop appropriate healthcare seeking behaviors.

This study was relatively based on large sample size. Moreover, the use of a triangulation of quantitative and qualitative methods with different participants is the strength of this study. However, this study is not without limitation. Firstly, recall bias is likely due to long recall period of six week. In addition, measurement of common childhood illnesses was taken based on the mothers' or care givers' perception of illness and was not validated clinically. Moreover, important predictors of healthcare seeking behavior such as real time to reach the nearest health facility were not available and taken an estimated time from respondents.

\section{Conclusion and Recommendations}

\subsection{Conclusion}

This study revealed that most mothers or care givers were sought healthcare from health facilities. Even though healthcare seeking practice in area was relatively better, seeking care from health facilities was delayed; only $31.5 \%$ of the total sick children seeking care within 24 hours after symptoms of an illness recognized by mothers or care givers. More than two-third of mothers or care givers $(70.9 \%)$ sought healthcare from health facilities after child's illnesses were worsened. Furthermore, place of residence, educational status of mothers, age of child, average family monthly income, perceived severity of illness and distance from health facilities were independent predictors mothers or care givers of healthcare seeking behavior for common childhood illnesses.

\subsection{Recommendations}

\subsubsection{For Regional Health Bureau and District Health Office}

Community focused health promotion of healthcare seeking behaviors and practices strategies like ICCM, CBNC and IMNCI should be strengthened by using health extension workers and increasing mother's or care giver's participation on child health care issues.

\subsubsection{For Health Facilities}

a) Healthcare service providers should give attention to service integration, counseling and educating mothers and caregivers, using missed opportunities during various contact time about common childhood illness and child care has paramount importance to improve healthcare seeking behaviors of the mothers or caregivers.

b) Health facilities in the district should give attention to health education and behavioral change communication to enhance healthcare seeking behavior of the mothers for child hood illnesses in the area.

c) Emphasis should be given for community based integrated management of childhood illnesses, since it is more likely to improve the healthcare seeking behaviors and child survival.

\subsubsection{For Health Post}

a) Implementation of essential programme such as Integrated Community Case Management (ICCM) and Community-Based Newborn Care (CBNC) strengthened, since implementation of these services in community setting could potentially improve access to child health services near to community.

b) To improve healthcare seeking behaviors of mothers, health education and behavioral change communication strategies should be strengthened at community level.

\subsubsection{For Health Care Workers Including HEWS}

Care providers should give special weight to strength promotion of preventive activities and prompt healthcare seeking behaviors. Because, it is vital to tackle problem of childhood illnesses.

\subsubsection{Researchers}

Further national wide research should be done on the issues. 


\section{Lists of Abbreviations}

a) AOR: Adjusted Odds Ratio

b) ARI: Acute Respiratory Infection

c) CBNC: Community- Based Newborn Care

d) FGD: Focus group discussions

e) HCSB: Healthcare Seeking Behavior

f) HEWs: Health Extension Workers

g) ICCM: Integrated Community Case Management of Childhood Illnesses

h) IMNCI: Integrated Management of Newborn and Childhood Illnesses

i) SPSS: Statistical Packages for Social Sciences

j) SSA: Sub-Saharan Africa

\section{Declarations}

\section{Ethics Approval and Consent to Participate}

Ethical approval was obtained from Ethical Review Committee of Debre Berhan University, College of Health Sciences. A formal letter was written to Kimbibit district health office for permission and support. Official letter was also obtained from district health office and submitted to the selected Kebele administrations. The study participants were informed about the purpose of the study and assure that participation was fully voluntary. Verbal consent was obtained from the participant. Confidentiality and the right of respondents were respected as well as each participant was explained about the purpose of the study. The respondents were assured that information would remain confidential and would be used for the purpose of this study only.

\section{Availability of Data and Materials}

The finding of this study is generated from the data collected and analyzed based on stated methods and materials. The original data supporting this finding are available from the corresponding author on reasonable request.

\section{Competing Interests}

The authors declare that they have no competing interests.

\section{Authors' Contributions}

HA participated in the design of the study, performed the data collection and the statistical analysis and served as the corresponding author of the manuscript. $Z K, R W$ and $T A$ supervised the study, ensured quality of the data, assisted in the analysis and interpretation of the data. All authors read and approved the manuscript.

\section{Authors' Information}

a) Habtamu Asrat is Public health specialist, Sheno Town, Ethiopia.

b) Zalalem Kaba is Water, Sanitation, Hygiene (WASH) and Neglected Tropical Diseases (NTDs) Program Coordinator, Nekemte town, Western Ethiopia. c) Robert Wondimu is Maternal and Child Health (MCH) Program Coordinator, SendafaBeke Town, Ethiopia.

d) Tola Abera is vice health of Barak Woreda Health Office, Oromia Regional State, Central Ethiopia.

\section{Acknowledgements}

We are grateful to Debre Berhan University, College of Medicine and Health Sciences, Department of Public Health for their cooperation during the study. Our special gratitude goes to Kimbibit district health office for their material support to perform this thesis and for giving their permission to conduct this study in the district. Finally, we were grateful to all the study participants who willingly gave their time to respond to the questionnaire, the data collectors, supervisors and FGD moderators for their full cooperation throughout the data collection period.

\section{References}

[1] Tsion A, Assefa T, Belachew T, Tegegn A, Deribew A. Mothers' Health Care Seeking Behavior for Childhood Illnesses in Derra District, Northshoa Zone, Oromia Regional State, Ethiopia. Ethiop J Heal Sci. 2008; 18 (6): 87-94.

[2] Anwar-ul-Haq, Durrani HM, Kumar R, Durrani SM. Recognizing the Danger Signs and Health Seeking Behaviour of Mothers in Childhood Illness in Karachi, Pakistan. Univers J Public Heal [Internet]. 2015; 3 (2): 49-54.

[3] Unicef, WHO, WBG UN. Child Mortality. 2018; 48.

[4] Dagnew AB, Tewabe T, Murugan R. Level of modern health care seeking behaviors among mothers having under five children in Dangila town, north West Ethiopia, 2016: A cross sectional study. Ital J Pediatr. 2018; 44 (1): 1-6.

[5] Yerpude PN, Jogdand KS, Shah JH, Thacker KB. A study of factors which determine health seeking behavior of mothers for their under five children in rural area of Gujarat. Int $\mathrm{J}$ Community Med Public Heal. 2017; 4 (11): 4169-73.

[6] The DHS Program. Ethiopia Demographic and Health Survey [Internet]. 2016. 187-189 p.

[7] Sisay S, Endalew G, Hadgu G. Assessment of Mothers / Care Givers Health Care Seeking Behavior for Childhood Illness in Rural Ensaro District, North Shoa Zone, Amhara Region, Ethiopia 2014. Glob J Life Sci Bilogical Res. 2015; 1 (1): 2034.

[8] Kolola T, Gezahegn T, Addisie M. Health care seeking behavior for common childhood illnesses in jeldu district, oromia regional state, Ethiopia. PLoS One [Internet]. 2016; 11 (10): 1-11.

[9] Begashaw B, Tessema F, Gesesew HA. Health Care Seeking Behavior in Southwest Ethiopia. Ciccozzi M, editor. PLoS One [Internet]. 2016 Sep 14; 11 (9): e0161014.

[10] Simieneh MM, Mengistu MY, Gelagay AA, Gebeyehu MT. Mothers ' health care seeking behavior and associated factors for common childhood illnesses, Northwest Ethiopia: community based cross-sectional study. BMC Health Serv Res. 2019; 4: 1-7. 
[11] Etea TD. Mother's perception and treatment seeking behaviour for childhood diarrhea in Dendi district, west Shoa, Ethiopia. Glob J Med Public Heal. 2014; 3 (3): 1-9.

[12] Kimbibit District Based Annual Plan of 2018/2019.

[13] Sreeramareddy CT, Shankar RP, Sreekumaran B V., Subba SH, Joshi HS, Ramachandran U. Care seeking behaviour for childhood illness-A questionnaire survey in western Nepal. BMC Int Health Hum Rights. 2006; 6: 1-10.

[14] World Health Organization. Guidelines for the Management of Common Childhood Illnesses. WHO Library Cataloguing-inPublication Data World. 2013.

[15] Awoke W. Prevalence of childhood illness and mothers'/caregivers' care seeking behavior in Bahir Dar, Ethiopia: A descriptive community based cross sectional study. Open J Prev Med [Internet]. 2013; 3 (2): 155-9.

[16] Lemeshow DWHS. Applied Logistic Regression Second Edition. 2013.

[17] Mahejabin F, Parveen S, Ibrahim M. Mother's/Care Giver's Health Seeking Behaviour During Childhood Illness in an Urban Slum of Dhaka city. Pulse. 2014; 7: 5-15.

[18] Gelaw YA, Biks GA, Alene KA. Effect of residence on mothers' health care seeking behavior for common childhood illness in Northwest Ethiopia: a community based comparative cross--sectional study. BMC Res Notes [Internet]. 2014 Oct 8; 7 (1): 705.

[19] Fissehaye T, Damte A, Fantahun A, Gebrekirstos K. Health care seeking behaviour of mothers towards diarrheal disease of children less than 5 years in Mekelle city, North Ethiopia. BMC Res Notes [Internet]. 2018; 1-7.

[20] Kanté AM, Gutierrez HR, Larsen AM, Jackson EF, Helleringer S, Exavery A, et al. Childhood Illness Prevalence and Health Seeking Behavior Patterns in Rural Tanzania. BMC Public Health. 2015; 15 (1): 1-12.

[21] Webair HH, Bin-Gouth A. Factors affecting health seeking behavior for common childhood illnesses in Yemen. Patient Prefer Adherence. 2013 Oct; 7: 1129.

[22] Adane M, Mengistie B, Mulat W, Kloos H, Medhin G. Utilization of health facilities and predictors of health-seeking behavior for under-five children with acute diarrhea in slums of Addis Ababa, Ethiopia: a community-based cross-sectional study. J Health Popul Nutr. 2017; 36 (1): 9.

[23] Weldesamuel GT, Alemayoh TT, Atalay HT, Zemichael TM, Weldesamuel G. Modern health-seeking behaviour and a ss ociated factors among mothers having under 5-years old children in Shire town, Tigray, Et hiopia: A cross-sectional study 2018. 2018; 1-6.

[24] Biresaw Nega, Kassawmar Angaw Bogale. Zelalem Mehari Nigussie. Health care seeking behavior and associated factor among mothers/caregivers of under-five children with acute diarrhea in Dangila zuria Woreda, North west Ethiopia, 2019.

[25] Ayalneh AA, Fetene DM, Lee TJ. Inequalities in health care utilization for common childhood illnesses in Ethiopia: Evidence from the 2011 Ethiopian Demographic and Health Survey. Int J Equity Health. 2017; 16 (1): 1-9.

[26] Sarker AR, Sultana M, Mahumud RA, Sheikh N, Van Der Meer R, Morton A. Prevalence and Health Care-Seeking Behavior for Childhood Diarrheal Disease in Bangladesh. Glob Pediatr Heal [Internet]. 2016.

[27] Geldsetzer P, Williams TC, Kirolos A, Mitchell S, Ratcliffe LA, Kohli-Lynch MK, et al. The recognition of and care seeking behaviour for childhood illness in developing countries: A systematic review. PLoS One. 2014; 9 (4).

[28] Wambui WM, Kimani S, Odhiambo E. Determinants of Health Seeking Behavior among Caregivers of Infants Admitted with Acute Childhood Illnesses at Kenyatta National Hospital, Nairobi, Kenya. Int J Pediatr. 2018; 2018: 1-11.

[29] Sigdel D, Onta M, Bista AP, Sharma K, Campus MN. International Journal of Health Sciences and Research. 2018; 8 (November): $177-84$. 